\title{
Advances and challenges in geroscience research: An update
}

\author{
A Yabluchanskiy ${ }^{1,2}$, Z Ungvari ${ }^{1,2,3,4}$, A Csiszar ${ }^{1,2,3}$, S Tarantini ${ }^{1,2}$ \\ ${ }^{1}$ Vascular Cognitive Impairment and Neurodegeneration Program Reynolds Oklahoma Center on Aging, \\ Department of Geriatric Medicine, University of Oklahoma Health Sciences Center, Oklahoma City, OK, USA \\ ${ }^{2}$ Translational Geroscience Laboratory, Department of Geriatric Medicine, University of Oklahoma Health Sciences \\ Center, Oklahoma City, Oklahoma, USA \\ ${ }^{3}$ Department of Medical Physics and Informatics, University of Szeged, Szeged, Hungary \\ ${ }^{4}$ Department of Pulmonology, Semmelweis University, Budapest, Hungary
}

Received: November 14, 2018

Accepted: November 26, 2018

\begin{abstract}
Aging remains the most pervasive risk factor for a wide range of chronic diseases that afflict modern societies. In the United States alone, incidence of age-related diseases (e.g., cardiovascular disease, stroke, Alzheimer's disease, vascular cognitive impairment and dementia, cancer, hypertension, type- 2 diabetes, chronic obstructive pulmonary disease, and osteoarthritis) is on the rise, posing an unsustainable socioeconomic burden even for the most developed countries. Tackling each and every age-related disease alone is proving to be costly and ineffective. The emerging field of geroscience has posed itself as an interdisciplinary approach that aims to understand the relationship between the biology of aging and the pathophysiology of chronic age-related diseases. According to the geroscience concept, aging is the single major risk factor that underlies several age-related chronic diseases, and manipulation of cellular and systemic aging processes can delay the manifestation and/or severity of these age-related chronic pathologies. The goal of this endeavor is to achieve health improvements by preventing/delaying the pathogenesis of several agerelated diseases simultaneously in the elderly population by targeting key cellular and molecular processes of aging instead of managing diseases of aging as they arise individually. In this review, we discuss recent advances in the field of geroscience, highlighting their implications for potential future therapeutic targets and the associated scientific challenges and opportunities that lay ahead.
\end{abstract}

Keywords: geroscience, mechanisms of aging, senolytic, senescence, inflamm-aging

\section{Introduction}

The western world is aging at a historically unprecedented rate, and in the $21^{\text {st }}$ century, we will experience the most dramatic aging demographic shift in human history. Scientific advances of the past decades have allowed for an impressive extension of lifespan in industrialized nations. For example, the overall life expectancy at birth is $\sim 80.2$ years (males: 77.4 years; females: 83.2 years) in the European Union. Combined with the decreasing birth rates, this results in a dramatic shift in the age structure of several Western societies (e.g., in Germany, Italy, Japan, as well as Hungary), which are predicted to have profound consequences on a broad range of economic, social, and political scenarios. There are

Corresponding author: Stefano Tarantini, $\mathrm{PhD}$

Vascular Cognitive Impairment and Neurodegeneration Program

Reynolds Oklahoma Center on Aging, Department of Geriatric Medicine

University of Oklahoma Health Sciences Center

975 N. E. 10th Street - BRC 1303, Oklahoma City, OK 73104, USA

E-mail: stefano-tarantini@ouhsc.edu 
growing concerns about the long-term viability of the currently existing social support systems, which are crucial for the well-being of the older generations.

The prevailing medical strategy for reducing the societal and healthcare impact of population aging is to increase disease-free survival ("health span"), by delaying the development of chronic age-related diseases (e.g., cardiovascular disease, stroke, Alzheimer's disease, vascular cognitive impairment and dementia, cancer, hypertension, type- 2 diabetes, chronic obstructive pulmonary disease, and osteoarthritis) and disability/institutionalization until a brief period at the end of life. The recently established field within aging research, termed "Geroscience," is focused on extension of health span (52). Geroscience aims to bridge two communities within the biogerontological research landscape. Traditionally, biogerontologists focus on studying the basic mechanisms underlying aging (e.g., studying Caenorhabditis elegans), whereas geriatricians seek to understand how to better the quality of life of our elder population. Using the geroscience approach, these two disciplines are merged attempting to better understand the bidirectional relationship between aging and age-related diseases. Aging is a complex and multifaceted process, and it is now understood that many cellular and molecular aging processes contribute to organismal aging. Thus, in theory, many potential points of intervention are targetable to slow aging; delaying age-related decline in organ functions; and decreasing the propensity for chronic diseases, disability, and mortality.

Current preclinical efforts to increase health span center on interfering with fundamental cellular and molecular processes of aging, such as heightened state of inflammation, increased oxidative stress, cellular senescence, mitochondrial dysregulation and cellular energetic dysfunction, impaired proteostasis, endocrine dysfunction, and reduced cellular and organismal stress resistance. In the past decade, growing understanding of cellular and molecular mechanism of aging in model organisms and then in laboratory rodents and non-human primates has allowed the scientific community to design and evaluate novel interventions [e.g., metformin $(6,29)$ and rapamycin $(10,15,22,32,34,35,39,49)$ ] aimed to interfere with key aging processes in humans as well, increasing disease-free survival. In this mini-review, we provide an update on recent geroscience research using a variety of experimental approaches, providing novel insights to elucidate common cellular and molecular pathways by which aging contribute to the pathogenesis of a vast array of age-related diseases.

\section{Recent Advances in Geroscience}

Research of fundamental, underlying mechanisms that drive the relationship between aging as a risk factor and chronic age-related pathologies is being conducted in multiple academic disciplines, including cellular biology and physiology, endocrinology, genetics, cognitive studies, molecular biology, metabolic biochemistry, molecular mechanisms that drive longevity, neurobiology, hypertension research, frailty research, immunology, cancer biology, Alzheimer's research, vascular biology, muscle and exercise physiology, and cerebrovascular and stroke research.

As expected, widespread age-related structural and functional changes across the whole network of an aging biological system will contribute to the pathogenesis of a plethora of diseases and disorders of multiple organs associated with old age including diseases of the heart, brain, eye, kidney, and the musculoskeletal system $(16,17,23,27)$. The present overview intends to highlight selected important current and emerging research directions in the field of geroscience research with the objective to facilitate prevention or the development of therapeutic treatments for age-related chronic diseases. 
Advances in insulin and growth hormone/insulin-like growth factor 1 (GH/IGF-1) signaling An important evolutionarily conserved mechanism of aging involves dysregulation of IGF-1 signaling $(4,7,14,63)$. Extant studies have previously demonstrated that age-related decline in IGF-1 levels contributes significantly to brain (53) and cardiovascular aging $(60,63,68)$. More recent evidence suggests that IGF-1 has sexually dimorphic, pleiotropic, and timedependent effects on health span, pathology, and lifespan $(4,7,14,55,63)$. Further studies are warranted to better understand the distinct roles of GH and IGF-1 signaling, the role of developmental effects of GH and IGF-1 in regulation of lifespan and health span (55), and the differential effects of circulating and paracrine IGF-1.

\section{Advances in genetics and epigenetics of aging}

New insights into genetic and epigenetic mechanisms in the aging process have the potential to offer new strategies and directions for discovery of new biomarkers and therapeutic interventions. Recent studies demonstrate that DNA methylation age is an accurate biomarker of chronological age and predicts lifespan $(33,36)$. A recent genome-wide association study indicated a critical role for human telomerase reverse transcriptase in regulating the epigenetic clock, in addition to its established role of compensating for cell replicationdependent telomere shortening (36). Recent studies have also identified DNA methylation as a potential mediator of age-related diabetes risk $(20,75)$ as well as playing a role in preserving cellular memory (11).

Another important area of geroscience research focuses on the role of interaction of the two mitochondrial genetic systems, including alterations in the mitochondrial DNA and dysregulation of the nuclear DNA-encoded mitochondrial genes, in the process of aging and the etiology of common age-related metabolic and degenerative diseases and cancer $(37,80)$.

\section{Advances in the role of dysregulation of immune responses and exacerbated sterile inflammation in aging}

As humans age, potentially detrimental changes occur in the immune system (48). For example, there is evidence from many studies that people aged over 65 years are more susceptible to infectious diseases. Novel findings suggest that chronic infection with human cytomegalovirus (CMV) might be altering the balance of immune responses in aging. This is of particular interest to the geroscience community, since over $90 \%$ of adults 80 years of age or older exhibit persistent infection with $\operatorname{CMV}(1,24,31,44,54)$, which replicates in the vascular endothelial cells and may contribute to a number of multiorgan age-related microvascular pathologies.

Aging is also associated with chronic low-grade sterile inflammation that has been termed "inflamm-aging." It is well accepted that this pro-inflammatory state is an important contributing factor to the development of a wide range of age-related diseases, including atherosclerosis and osteoarthritis $(16,17,27)$. Osteoarthritis is a chronic, painful inflammatory joint disease that affects approximately $40 \%$ of adults over 70 years. There is growing evidence that synergistic interaction of aging and lifestyle factors that promote chronic inflammation, such as obesity, significantly increases the risk for osteoarthritis (27). Recent studies have identified mechanisms contributing to osteoarthritis progression in aging and obesity including increased innate immune responses, macrophage activation, and proinflammatory cytokine production (27). Synergistic interaction of aging and obesity was also shown to promote vascular inflammation and dysfunction in aging $(70,71,78)$. 


\section{Advances in cellular senescence}

Extant evidence shows that during aging, the increased DNA damage contributes to the growing number senescent cells in the tissues. Senescent cells express a pro-oxidative, pro-inflammatory phenotype called the senescence-associated secretory phenotype. In recent years, the concept has emerged that presence of senescent cells contributes to the pathogenesis of a wide range of age-related inflammatory diseases $(25,81)$, such as osteoarthritis (26) and atherosclerosis (9). Recent breakthrough studies demonstrate that transplanting relatively small numbers of senescent cells into young mice is sufficient to cause persistent aging-like physical dysfunction, induce spreading of cellular senescence to the host tissues and to reduce survival $(83,85)$, indicating the potency of senescent cells in shortening health- and lifespan. It is expected that new studies will lead to a better understanding of the molecular mechanisms underlying the activation of senescence pathways $(12,42,51)$. This knowledge will enable the development of novel treatments aimed at removing the senescent cellular burden to increase health span by delaying/preventing age-associated pathologies $(26,46)$.

\section{Advances in mTOR signaling}

There is growing evidence suggesting that inhibition of the evolutionarily conserved mammalian target of rapamycin (mTOR, also known as mechanistic target of rapamycin) pathway may have protective effects against aging $(3,22)$. Novel findings have identified that the mTOR pathway plays an integral role in the coordination of metabolism, protein synthesis, cell growth, and inflammation whereby mTOR regulates cellular stress resistance, modulates aging processes, and determines mammalian lifespan $(3,30,66,77)$. Inhibition of mTOR was shown to exert multifaceted anti-aging effects in multiple organ systems, including significant vasoprotective effects, protecting endothelial function $(34,35)$ and the blood-brain barrier (BBB) in models of Alzheimer's disease and vascular cognitive impairment (79).

\section{Advances in cardiovascular aging}

Within the past decade, there has been a newfound interest in the study of the aging heart and vasculature. New evidence suggests that in addition to promoting atherogenesis, aging significantly impacts the structure and function of cells within the wall of microvessels as well (72). Fully within the scope of the geroscience initiative, recent studies have indicated that age-related alterations of the brain microcirculation can initiate the pathogenesis of a spectrum of diseases ranging from vascular cognitive impairment to Alzheimer's disease $(67,72)$. The high energetic requirements of the brain's neuronal activity must be closely matched by an adequate supply of oxygen and nutrients. This is achieved by a physiological homeostatic mechanism called neurovascular coupling. Unfortunately, this activitydependent increase of cerebral blood flow becomes compromised during aging (59). The endothelium is an actively involved component of the neurovascular unit, which plays a crucial role in propagation of vasodilation during functional hyperemia. NO released from the cerebral microvascular endothelium is a critical vasodilator that regulates microvascular resistance and thereby cerebral blood perfusion. Previous studies demonstrate that aging leads to impairment of neurovascular coupling responses due to an age-related impairment of NO bioavailability (59). It was recently shown using mice with genetic modulation of eNOS expression and pharmacological inhibition of NO synthesis that microvascular NO release plays a critical role in the mediation of neurovascular coupling responses, providing an important theoretical framework fueling further research in cerebromicrovascular aging (59). 
Recent advances in the study of cellular and molecular processes underlying neurovascular coupling has allowed for developing novel therapeutic strategies to restore microvascular blood flow, rescue neurovascular responses, and thus improving cognition in older individuals $(62,64)$. Endothelial dysfunction is pervasive during vascular aging, thus it is likely that interventional strategies that improve cerebral blood flow will exert beneficial effects on other vascular beds as well in older individuals $(62,72)$. New developments in understanding the contributions of altered microenvironment in the aged vascular wall (74) and the role of agerelated alteration in the extracellular matrix (19) will lead to the identification of new targets to prevent diseases ranging from hemorrhagic stroke to aortic aneurysms.

BBB disruption is another important factor, which plays a key role in increased neuroinflammation in the aging brain $(58,69,73)$, likely contributing to the pathogenesis of Alzheimer's disease and vascular cognitive impairment $(56,57)$. There is newly found evidence that impaired microvascular resilience to stressors exacerbates BBB disruption induced by hypertension and metabolic diseases, which likely have direct relevance for impaired synaptic function and cognitive decline $(61,69)$.

Recent advances in cardiac aging improved our understanding of the role of age-related alteration in the extracellular matrix (38), bioenergetics, and stem cell biology. Recent studies indicate that there might be striking similarity between human and canine aging processes (76). Newfound data suggest that companion dogs may be a particularly useful animal model for understanding mechanisms contributing to cardiovascular aging and for developing and testing interventions to ameliorate age-related cardiovascular dysfunction.

\section{Advances in brain injury and cognition in aging}

Traumatic brain injury (TBI) and other brain-related injuries are a serious health problem that can lead to long-lasting cognitive deficits in older individuals. In addition to its high mortality $(35 \%-40 \%)$, survivors are left with a broad spectrum of symptoms including short-term memory problems, behavioral disabilities, and other health symptoms. Recent evidence suggests that increased mitochondrial production of reactive oxygen species (ROS) in the aged cerebral microvessels may contribute to the secondary damage to the brain following the initial brain trauma. Future research should determine the efficacy of mitochondriatargeted antioxidants (62) in aged preclinical models of TBI.

\section{Advances in pharmacological therapies to delay aging}

The gathering evidence on the mechanisms underlying age-related pathophysiological alterations holds promise for the potential development of novel clinical diagnostic methods and new therapeutic strategies. Despite recent advances in geroscience, the cellular, and molecular mechanisms involved in the pathogenesis of age-related diseases are incompletely understood. Studies aimed to test the effects of anti-aging intervention on a wide range of basic cellular mechanisms of aging, and physiological functions of other organ systems are underway and hold powerful opportunities to slow down the aging process. Examples of new studies that have identified novel pathways and potential treatments include the demonstration of the role of increased mitochondrial production of ROS that critically contributes to the genesis of microvascular endothelial dysfunction in older organisms (62). Treatment with the recently discovered mitochondrial-targeted antioxidant peptide SS-31 was reported to rescue microvascular endothelial function and neurovascular coupling responses, improving cognition in aged mice (62). In the upcoming years, progress is expected with the combined use of dietary interventions (11) and supplements with anti-aging efficacy $(41,45)$. In the past few 
years, several therapeutic strategies have emerged to target senescent cells for delaying the aging process and preventing the progression of chronic diseases $(2,5,28,65)$. Recent studies have identified dasatinib plus quercetin (85), heat shock protein 90 (HSP90) inhibitors (18), fisetin (86), mouse double minute 2 homolog antagonists (82) and agents acting on oxidation resistance protein 1 (87), and B-cell lymphoma 2 (8) as a potential senolytic agents that could extend health span and/or lifespan. Research efforts that identify novel gene targets, which regulate aging processes in model organisms $(30,47)$, also provide a potentially valuable approach for drug repurposing (13) to improve outcomes in elderly patients suffering from age-related chronic diseases.

\section{Summary}

On the whole, thanks to recent important advances during the past couple of years, the field of geroscience has enjoyed an explosive growth. The concept has been increasingly accepted that by targeting fundamental aging processes, it may be possible to ameliorate a vast array of human diseases associated with old age and is destined to revolutionize the way we think about aging research $(6,28,29,43,50,84,85,88)$. Because we are just at the beginning of this paradigm shift, further interdisciplinary studies are needed that bridge clinical research and basic animal model research to learn more about the underlying mechanisms of aging. Using the perspective of geroscience in novel models of aging and age-related diseases will be rewarding. Important areas for future translational research in the field of geroscience include modulation of the proteasome and autophagy pathways, identification of treatments that restore cellular energetics, and development of novel dietary interventions to delay aging $(11,21,40)$. In geriatric medicine, frailty is an important problem. Frail older people exhibit impaired stress resilience, prone to dependency, and have reduced life expectancy. The geroscience approach to aging research will facilitate the understanding of aging processes that compromise the function of multiple organ systems simultaneously and thereby contributing to frailty, and will improve these health outcomes, decreasing demand for medical and social care.

\section{Acknowledgements}

This work was supported by grants from the American Heart Association (to ST), the NIH-supported Oklahoma Shared Clinical and Translational Resources (to AY, NIGMS U54GM104938), the Oklahoma Center for the Advancement of Science and Technology (to AC, ZU, and AY), and the Presbyterian Health Foundation (to ZU, AC, and AY).

\section{REFERENCES}

1. Aiello AE, Chiu YL, Frasca D: How does cytomegalovirus factor into diseases of aging and vaccine responses, and by what mechanisms? GeroScience 39, 261-271 (2017)

2. Akkad H, Cacciani N, Llano-Diez M, Corpeno Kalamgi R, Tchkonia T, Kirkland JL, Larsson L: Vamorolone treatment improves skeletal muscle outcome in a critical illness myopathy rat model. Acta Physiol. (Oxf). e13172 (2018) [Epub ahead of print]

3. An JY, Quarles EK, Mekvanich S, Kang A, Liu A, Santos D, Miller RA, Rabinovitch PS, Cox TC, Kaeberlein M: Rapamycin treatment attenuates age-associated periodontitis in mice. GeroScience 39, 457-463 (2017)

4. Ashpole NM, Logan S, Yabluchanskiy A, Mitschelen MC, Yan H, Farley JA, Hodges EL, Ungvari Z, Csiszar A, Chen S, Georgescu C, Hubbard GB, Ikeno Y, Sonntag WE: IGF-1 has sexually dimorphic, pleiotropic, and timedependent effects on healthspan, pathology, and lifespan. GeroScience 39, 129-145 (2017) 
5. Baker DJ, Wijshake T, Tchkonia T, LeBrasseur NK, Childs BG, van de Sluis B, Kirkland JL, van Deursen JM: Clearance of p16Ink4a-positive senescent cells delays ageing-associated disorders. Nature 479, 232-236 (2011)

6. Barzilai N, Crandall JP, Kritchevsky SB, Espeland MA: Metformin as a tool to target aging. Cell Metab. 23, 1060-1065 (2016)

7. Bennis MT, Schneider A, Victoria B, Do A, Wiesenborn DS, Spinel L, Gesing A, Kopchick JJ, Siddiqi SA, Masternak MM: The role of transplanted visceral fat from the long-lived growth hormone receptor knockout mice on insulin signaling. GeroScience 39, 51-59 (2017)

8. Chang J, Wang Y, Shao L, Laberge RM, Demaria M, Campisi J, Janakiraman K, Sharpless NE, Ding S, Feng W, Luo Y, Wang X, Aykin-Burns N, Krager K, Ponnappan U, Hauer-Jensen M, Meng A, Zhou D: Clearance of senescent cells by ABT263 rejuvenates aged hematopoietic stem cells in mice. Nat. Med. 22, $78-83$ (2016)

9. Childs BG, Baker DJ, Wijshake T, Conover CA, Campisi J, van Deursen JM: Senescent intimal foam cells are deleterious at all stages of atherosclerosis. Science 354, 472-477 (2016)

10. Dai DF, Karunadharma PP, Chiao YA, Basisty N, Crispin D, Hsieh EJ, Chen T, Gu H, Djukovic D, Raftery D, Beyer RP, MacCoss MJ, Rabinovitch PS: Altered proteome turnover and remodeling by short-term caloric restriction or rapamycin rejuvenate the aging heart. Aging Cell 13, 529-539 (2014)

11. Di Francesco A, Di Germanio C, Bernier M, de Cabo R: A time to fast. Science 362, 770-775 (2018)

12. Donato AJ, Machin DR, Lesniewski LA: Mechanisms of dysfunction in the aging vasculature and role in agerelated disease. Circ. Res. 123, 825-848 (2018)

13. Donertas HM, Fuentealba Valenzuela M, Partridge L, Thornton JM: Gene expression-based drug repurposing to target aging. Aging Cell 17, e12819 (2018)

14. Fang Y, McFadden S, Darcy J, Hill CM, Huber JA, Verhulst S, Kopchick JJ, Miller RA, Sun LY, Bartke A: Differential effects of early-life nutrient restriction in long-lived GHR-KO and normal mice. GeroScience 39, 347-356 (2017)

15. Fok WC, Bokov A, Gelfond J, Yu Z, Zhang Y, Doderer M, Chen Y, Javors M, Wood WH, 3rd, Becker KG, Richardson A, Perez VI: Combined treatment of rapamycin and dietary restriction has a larger effect on the transcriptome and metabolome of liver. Aging Cell 13, 311-319 (2014)

16. Fu Y, Huebner JL, Kraus VB, Griffin TM: Effect of aging on adipose tissue inflammation in the knee joints of F344BN Rats. J. Gerontol. A Biol. Sci. Med. Sci. 71, 1131-1140 (2016)

17. Fu Y, Kinter M, Hudson J, Humphries KM, Lane RS, White JR, Hakim M, Pan Y, Verdin E, Griffin TM: Aging promotes sirtuin 3-dependent cartilage superoxide dismutase 2 acetylation and osteoarthritis. Arthritis Rheumatol. 68, 1887-1898 (2016)

18. Fuhrmann-Stroissnigg H, Ling YY, Zhao J, McGowan SJ, Zhu Y, Brooks RW, Grassi D, Gregg SQ, Stripay JL, Dorronsoro A, Corbo L, Tang P, Bukata C, Ring N, Giacca M, Li X, Tchkonia T, Kirkland JL, Niedernhofer LJ, Robbins PD: Identification of HSP90 inhibitors as a novel class of senolytics. Nat. Commun. 8, 422 (2017)

19. Fulop GA, Ramirez-Perez FI, Kiss T, Tarantini S, Valcarcel Ares MN, Toth P, Yabluchanskiy A, Conley SM, Ballabh P, Martinez-Lemus LA, Ungvari Z, Csiszar A: IGF-1 deficiency promotes pathological remodeling of cerebral arteries: A potential mechanism contributing to the pathogenesis of intracerebral hemorrhages in aging. J. Gerontol. A Biol. Sci. Med. Sci. (2018)

20. Grant CD, Jafari N, Hou L, Li Y, Stewart JD, Zhang G, Lamichhane A, Manson JE, Baccarelli AA, Whitsel EA, Conneely KN: A longitudinal study of DNA methylation as a potential mediator of age-related diabetes risk. GeroScience 39, 475-489 (2017)

21. Gutierrez-Casado E, Khraiwesh H, Lopez-Dominguez JA, Montero-Guisado J, Lopez-Lluch G, Navas P, de Cabo R, Ramsey JJ, Gonzalez-Reyes JA, Villalba JM: The impact of aging, calorie restriction and dietary fat on mitochondrial ultrastructure, dynamics and autophagy markers in mouse skeletal muscle. J. Gerontol. A Biol. Sci. Med. Sci. (2018)

22. Harrison DE, Strong R, Sharp ZD, Nelson JF, Astle CM, Flurkey K, Nadon NL, Wilkinson JE, Frenkel K, Carter CS, Pahor M, Javors MA, Fernandez E, Miller RA: Rapamycin fed late in life extends lifespan in genetically heterogeneous mice. Nature 460, 392-395 (2009)

23. Hodes RJ, Sierra F, Austad SN, Epel E, Neigh GN, Erlandson KM, Schafer MJ, LeBrasseur NK, Wiley C, Campisi J, Sehl ME, Scalia R, Eguchi S, Kasinath BS, Halter JB, Cohen HJ, Demark-Wahnefried W, Ahles TA, Barzilai N, Hurria A, Hunt PW: Disease drivers of aging. Ann. N Y Acad. Sci. 1386, 45-68 (2016)

24. Jackson SE, Redeker A, Arens R, van Baarle D, van den Berg SPH, Benedict CA, Cicin-Sain L, Hill AB, Wills MR: CMV immune evasion and manipulation of the immune system with aging. GeroScience 39, 273-291 (2017)

25. Jeon OH, David N, Campisi J, Elisseeff JH: Senescent cells and osteoarthritis: a painful connection. J. Clin. Invest. 128, 1229-1237 (2018) 
26. Jeon OH, Kim C, Laberge RM, Demaria M, Rathod S, Vasserot AP, Chung JW, Kim DH, Poon Y, David N, Baker DJ, van Deursen JM, Campisi J, Elisseeff JH: Local clearance of senescent cells attenuates the development of post-traumatic osteoarthritis and creates a pro-regenerative environment. Nat. Med. 23, 775-781 (2017)

27. Kalaitzoglou E, Griffin TM, Humphrey MB: Innate immune responses and osteoarthritis. Curr. Rheumatol. Rep. 19, 45 (2017)

28. Khosla S, Farr JN, Kirkland JL: Inhibiting cellular senescence: a new therapeutic paradigm for age-related osteoporosis. J. Clin. Endocrinol. Metab. 103, 1282-1290 (2018)

29. Kulkarni AS, Brutsaert EF, Anghel V, Zhang K, Bloomgarden N, Pollak M, Mar JC, Hawkins M, Crandall JP, Barzilai N: Metformin regulates metabolic and nonmetabolic pathways in skeletal muscle and subcutaneous adipose tissues of older adults. Aging Cell 17, e12723 (2018)

30. Lee MB, Carr DT, Kiflezghi MG, Zhao YT, Kim DB, Thon S, Moore MD, Li MAK, Kaeberlein M: A system to identify inhibitors of mTOR signaling using high-resolution growth analysis in Saccharomyces cerevisiae. GeroScience (2017) [Epub ahead of print]

31. Leng SX, Kamil J, Purdy JG, Lemmermann NA, Reddehase MJ, Goodrum FD: Recent advances in CMV tropism, latency, and diagnosis during aging. GeroScience 39, 251-259 (2017)

32. Lesniewski LA, Seals DR, Walker AE, Henson GD, Blimline MW, Trott DW, Bosshardt GC, LaRocca TJ, Lawson BR, Zigler MC, Donato AJ: Dietary rapamycin supplementation reverses age-related vascular dysfunction and oxidative stress, while modulating nutrient-sensing, cell cycle, and senescence pathways. Aging Cell 16, 17-26 (2017)

33. Levine ME, Lu AT, Quach A, Chen BH, Assimes TL, Bandinelli S, Hou L, Baccarelli AA, Stewart JD, Li Y, Whitsel EA, Wilson JG, Reiner AP, Aviv A, Lohman K, Liu Y, Ferrucci L, Horvath S: An epigenetic biomarker of aging for lifespan and healthspan. Aging (Albany NY) 10, 573-591 (2018)

34. Lin AL, Jahrling JB, Zhang W, DeRosa N, Bakshi V, Romero P, Galvan V, Richardson A: Rapamycin rescues vascular, metabolic and learning deficits in apolipoprotein E4 transgenic mice with pre-symptomatic Alzheimer's disease. J. Cereb. Blood Flow Metab. 37, 217-226 (2017)

35. Lin AL, Zheng W, Halloran JJ, Burbank RR, Hussong SA, Hart MJ, Javors M, Shih YY, Muir E, Solano Fonseca R, Strong R, Richardson AG, Lechleiter JD, Fox PT, Galvan V: Chronic rapamycin restores brain vascular integrity and function through NO synthase activation and improves memory in symptomatic mice modeling Alzheimer's disease. J. Cereb. Blood Flow Metab. 33, 1412-1421 (2013)

36. Lu AT, Xue L, Salfati EL, Chen BH, Ferrucci L, Levy D, Joehanes R, Murabito JM, Kiel DP, Tsai PC, Yet I, Bell JT, Mangino M, Tanaka T, McRae AF, Marioni RE, Visscher PM, Wray NR, Deary IJ, Levine ME, Quach A, Assimes T, Tsao PS, Absher D, Stewart JD, Li Y, Reiner AP, Hou L, Baccarelli AA, Whitsel EA, Aviv A, Cardona A, Day FR, Wareham NJ, Perry JRB, Ong KK, Raj K, Lunetta KL, Horvath S: GWAS of epigenetic aging rates in blood reveals a critical role for TERT. Nat. Commun. 9, 387 (2018)

37. McManus MJ, Picard M, Chen HW, De Haas HJ, Potluri P, Leipzig J, Towheed A, Angelin A, Sengupta P, Morrow RM, Kauffman BA, Vermulst M, Narula J, Wallace DC: Mitochondrial DNA variation dictates expressivity and progression of nuclear DNA mutations causing cardiomyopathy. Cell Metab. (2018) [Epub ahead of print]

38. Meschiari CA, Ero OK, Pan H, Finkel T, Lindsey ML: The impact of aging on cardiac extracellular matrix. GeroScience 39, 7-18 (2017)

39. Miller RA, Harrison DE, Astle CM, Baur JA, Boyd AR, de Cabo R, Fernandez E, Flurkey K, Javors MA, Nelson JF, Orihuela CJ, Pletcher S, Sharp ZD, Sinclair D, Starnes JW, Wilkinson JE, Nadon NL, Strong R: Rapamycin, but not resveratrol or simvastatin, extends life span of genetically heterogeneous mice. J. Gerontol. A Biol. Sci. Med. Sci. 66, 191-201 (2011)

40. Mitchell SJ, Bernier M, Mattison JA, Aon MA, Kaiser TA, Anson RM, Ikeno Y, Anderson RM, Ingram DK, de Cabo R: Daily fasting improves health and survival in male mice independent of diet composition and calories. Cell Metab. (2018) [Epub ahead of print]

41. Moore TL, Bowley B, Shultz P, Calderazzo S, Shobin E, Killiany RJ, Rosene DL, Moss MB: Chronic curcumin treatment improves spatial working memory but not recognition memory in middle-aged rhesus monkeys. GeroScience 39, 571-584 (2017)

42. Morgan RG, Donato AJ, Walker AE: Telomere uncapping and vascular aging. Am. J. Physiol. Heart Circ. Physiol. 315, H1-H5 (2018)

43. Newman JC, Milman S, Hashmi SK, Austad SN, Kirkland JL, Halter JB, Barzilai N: Strategies and challenges in clinical trials targeting human aging. J. Gerontol. A Biol. Sci. Med. Sci. 71, 1424-1434 (2016) 
44. Nikolich-Zugich J, van Lier RAW: Cytomegalovirus (CMV) research in immune senescence comes of age: overview of the 6th International Workshop on CMV and Immunosenescence. GeroScience 39, 245-249 (2017)

45. Pearson KJ, Baur JA, Lewis KN, Peshkin L, Price NL, Labinskyy N, Swindell WR, Kamara D, Minor RK, Perez E, Jamieson HA, Zhang Y, Dunn SR, Sharma K, Pleshko N, Woollett LA, Csiszar A, Ikeno Y, Le Couteur D, Elliott PJ, Becker KG, Navas P, Ingram DK, Wolf NS, Ungvari Z, Sinclair DA, de Cabo R: Resveratrol delays age-related deterioration and mimics transcriptional aspects of dietary restriction without extending life span. Cell Metab. 8, 157-168 (2008)

46. Perrott KM, Wiley CD, Desprez PY, Campisi J: Apigenin suppresses the senescence-associated secretory phenotype and paracrine effects on breast cancer cells. GeroScience 39, 161-173 (2017)

47. Podshivalova K, Kerr RA, Kenyon C: How a mutation that slows aging can also disproportionately extend end-of-life decrepitude. Cell Rep. 19, 441-450 (2017)

48. Rais M, Wilson RM, Urbanski HF, Messaoudi I: Androgen supplementation improves some but not all aspects of immune senescence in aged male macaques. GeroScience 39, 373-384 (2017)

49. Richardson A, Galvan V, Lin AL, Oddo S: How longevity research can lead to therapies for Alzheimer's disease: the rapamycin story. Exp. Gerontol. 68, 51-58 (2015)

50. Roos CM, Zhang B, Palmer AK, Ogrodnik MB, Pirtskhalava T, Thalji NM, Hagler M, Jurk D, Smith LA, Casaclang-Verzosa G, Zhu Y, Schafer MJ, Tchkonia T, Kirkland JL, Miller JD: Chronic senolytic treatment alleviates established vasomotor dysfunction in aged or atherosclerotic mice. Aging Cell 15, 973-977 (2016)

51. Rossman MJ, Kaplon RE, Hill SD, McNamara MN, Santos-Parker JR, Pierce GL, Seals DR, Donato AJ: Endothelial cell senescence with aging in healthy humans: prevention by habitual exercise and relation to vascular endothelial function. Am. J. Physiol. Heart Circ. Physiol. 313, H890-H895 (2017)

52. Sierra F, Kohanski R: Geroscience and the trans-NIH Geroscience Interest Group, GSIG. GeroScience 39, 1-5 (2017)

53. Sonntag WE, Deak F, Ashpole N, Toth P, Csiszar A, Freeman W, Ungvari Z: Insulin-like growth factor-1 in CNS and cerebrovascular aging. Front Aging Neurosci. 5, 27 (2013)

54. Souquette A, Frere J, Smithey M, Sauce D, Thomas PG: A constant companion: immune recognition and response to cytomegalovirus with aging and implications for immune fitness. GeroScience 39, 293-303 (2017)

55. Sun LY, Fang Y, Patki A, Koopman JJ, Allison DB, Hill CM, Masternak MM, Darcy J, Wang J, McFadden S, Bartke A: Longevity is impacted by growth hormone action during early postnatal period. Elife 6, e24059 (2017)

56. Sweeney MD, Sagare AP, Zlokovic BV: Blood-brain barrier breakdown in Alzheimer disease and other neurodegenerative disorders. Nat. Rev. Neurol. 14, 133-150 (2018)

57. Sweeney MD, Zhao Z, Montagne A, Nelson AR, Zlokovic BV: Blood-brain barrier: from physiology to disease and back. Physiol. Rev. 99, 21-78 (2019)

58. Tarantini S, Fulop GA, Kiss T, Farkas E, Zolei-Szenasi D, Galvan V, Toth P, Csiszar A, Ungvari Z, Yabluchanskiy A: Demonstration of impaired neurovascular coupling responses in TG2576 mouse model of Alzheimer's disease using functional laser speckle contrast imaging. GeroScience 39, 465-473 (2017)

59. Tarantini S, Tran CHT, Gordon GR, Ungvari Z, Csiszar A: Impaired neurovascular coupling in aging and Alzheimer's disease: contribution of astrocyte dysfunction and endothelial impairment to cognitive decline. Exp. Gerontol. 94, 52-58 (2017)

60. Tarantini S, Tucsek Z, Valcarcel-Ares M, Toth P, Gautam T, Giles C, Ballabh P, Wei Y, Wren J, Ashpole N, Sonntag W, Ungvari Z, Csiszar A: Circulating IGF-1 deficiency exacerbates hypertension-induced microvascular rarefaction in the mouse hippocampus and retrosplenial cortex: implications for cerebromicrovascular and brain aging. Age (Dordr) 38, 273-289 (2016)

61. Tarantini S, Valcarcel-Ares MN, Yabluchanskiy A, Tucsek Z, Hertelendy P, Kiss T, Gautam T, Zhang XA, Sonntag WE, de Cabo R, Farkas E, Elliott ME, Kinter MT, Deak F, Ungvari Z, Csiszar A: Nrf2 deficiency exacerbates obesity-induced oxidative stress, neurovascular dysfunction, blood brain barrier disruption, neuroinflammation, amyloidogenic gene expression and cognitive decline in mice, mimicking the aging phenotype. J. Gerontol. A Biol. Sci. Med. Sci. 73, 853-863 (2018)

62. Tarantini S, Valcarcel-Ares NM, Yabluchanskiy A, Fulop GA, Hertelendy P, Gautam T, Farkas E, Perz A, Rabinovitch PS, Sonntag WE, Csiszar A, Ungvari Z: Treatment with the mitochondrial-targeted antioxidant peptide SS-31 rescues neurovascular coupling responses and cerebrovascular endothelial function and improves cognition in aged mice. Aging Cell 17, e12731 (2018)

63. Tarantini S, Valcarcel-Ares NM, Yabluchanskiy A, Springo Z, Fulop GA, Ashpole N, Gautam T, Giles CB, Wren JD, Sonntag WE, Csiszar A, Ungvari Z: Insulin-like growth factor 1 deficiency exacerbates hypertensioninduced cerebral microhemorrhages in mice, mimicking the aging phenotype. Aging Cell 16, 469-479 (2017) 
64. Tarantini S, Yabluchanksiy A, Fulop GA, Hertelendy P, Valcarcel-Ares MN, Kiss T, Bagwell JM, O'Connor D, Farkas E, Sorond F, Csiszar A, Ungvari Z: Pharmacologically induced impairment of neurovascular coupling responses alters gait coordination in mice. GeroScience 39, 601-614 (2017)

65. Tchkonia T, Kirkland JL: Aging, cell senescence, and chronic disease: emerging therapeutic strategies. JAMA 320, 1319-1320 (2018)

66. Tian Q, Gromov P, Clement JH, Wang Y, Riemann M, Weih F, Sun XX, Dai MS, Fedorov LM: RHEB1 insufficiency in aged male mice is associated with stress-induced seizures. GeroScience 39, 557-570 (2017)

67. Toth P, Tarantini S, Csiszar A, Ungvari Z: Functional vascular contributions to cognitive impairment and dementia: mechanisms and consequences of cerebral autoregulatory dysfunction, endothelial impairment, and neurovascular uncoupling in aging. Am. J. Physiol. Heart Circ. Physiol. 312, H1-H20 (2017)

68. Toth P, Tucsek Z, Tarantini S, Sosnowska D, Gautam T, Mitschelen M, Koller A, Sonntag WE, Csiszar A, Ungvari Z: IGF-1 deficiency impairs cerebral myogenic autoregulation in hypertensive mice. J. Cereb. Blood Flow Metab. 34, 1887-1897 (2014)

69. Tucsek Z, Noa Valcarcel-Ares M, Tarantini S, Yabluchanskiy A, Fulop G, Gautam T, Orock A, Csiszar A, Deak F, Ungvari Z: Hypertension-induced synapse loss and impairment in synaptic plasticity in the mouse hippocampus mimics the aging phenotype: implications for the pathogenesis of vascular cognitive impairment. GeroScience 39, 385-406 (2017)

70. Tucsek Z, Toth P, Sosnowsk D, Gautam T, Mitschelen M, Koller A, Szalai G, Sonntag WE, Ungvari Z, Csiszar A: Obesity in aging exacerbates blood brain barrier disruption, neuroinflammation and oxidative stress in the mouse hippocampus: effects on expression of genes involved in beta-amyloid generation and Alzheimer's disease. J. Gerontol. A Biol. Sci. Med. Sci. 69, 1212-1226 (2014)

71. Tucsek Z, Toth P, Tarantini S, Sosnowska D, Gautam T, Warrington JP, Giles CB, Wren JD, Koller A, Ballabh $\mathrm{P}$, Sonntag WE, Ungvari Z, Csiszar A: Aging exacerbates obesity-induced cerebromicrovascular rarefaction, neurovascular uncoupling, and cognitive decline in mice. J. Gerontol. A Biol. Sci. Med. Sci. 69, 1339-1352 (2014)

72. Ungvari Z, Tarantini S, Donato AJ, Galvan V, Csiszar A: Mechanisms of vascular aging. Circ. Res. 123, 849-867 (2018)

73. Ungvari Z, Tarantini S, Hertelendy P, Valcarcel-Ares MN, Fülöp GÁ, Logan S, Kiss T, Farkas E, Csiszar A, Yabluchanskiy A: Cerebromicrovascular dysfunction predicts cognitive decline and gait abnormalities in a mouse model of whole brain irradiation-induced accelerated brain senescence. GeroScience 39, 33-42 (2017)

74. Ungvari Z, Valcarcel-Ares MN, Tarantini S, Yabluchanskiy A, Fulop GA, Kiss T, Csiszar A: Connective tissue growth factor (CTGF) in age-related vascular pathologies. GeroScience 39, 491-498 (2017)

75. Unnikrishnan A, Jackson J, Matyi SA, Hadad N, Wronowski B, Georgescu C, Garrett KP, Wren JD, Freeman WM, Richardson A: Role of DNA methylation in the dietary restriction mediated cellular memory. GeroScience 39, 331-345 (2017)

76. Urfer SR, Kaeberlein TL, Mailheau S, Bergman PJ, Creevy KE, Promislow DE, Kaeberlein M: Asymptomatic heart valve dysfunction in healthy middle-aged companion dogs and its implications for cardiac aging. GeroScience 39, 43-50 (2017)

77. Urfer SR, Kaeberlein TL, Mailheau S, Bergman PJ, Creevy KE, Promislow DE, Kaeberlein M: A randomized controlled trial to establish effects of short-term rapamycin treatment in 24 middle-aged companion dogs. GeroScience 39, 117-127 (2017)

78. Valcarcel-Ares MN, Tucsek Z, Kiss T, Giles CB, Tarantini S, Yabluchanskiy A, Balasubramanian P, Gautam T, Galvan V, Ballabh P, Richardson A, Freeman WM, Wren JD, Deak F, Ungvari Z, Csiszar A: Obesity in aging exacerbates neuroinflammation, dysregulating synaptic function-related genes and altering eicosanoid synthesis in the mouse hippocampus: potential role in impaired synaptic plasticity and cognitive decline. J. Gerontol. A Biol. Sci. Med. Sci. (2018) [Epub ahead of print]

79. Van Skike CE, Jahrling JB, Olson AB, Sayre NL, Hussong SA, Ungvari Z, Lechleiter JD, Galvan V: Inhibition of mTOR protects the blood-brain barrier in models of Alzheimer's disease and vascular cognitive impairment. Am J Physiol Heart Circ Physiol. 314, H693-H703 (2018)

80. Wallace DC: Mitochondrial DNA mutations in disease and aging. Environ. Mol. Mutagen. 51, 440-450 (2010)

81. Wiley CD, Flynn JM, Morrissey C, Lebofsky R, Shuga J, Dong X, Unger MA, Vijg J, Melov S, Campisi J: Analysis of individual cells identifies cell-to-cell variability following induction of cellular senescence. Aging Cell 16, 1043-1050 (2017)

82. Wiley CD, Schaum N, Alimirah F, Lopez-Dominguez JA, Orjalo AV, Scott G, Desprez PY, Benz C, Davalos AR, Campisi J: Small-molecule MDM2 antagonists attenuate the senescence-associated secretory phenotype. Sci. Rep. 8, 2410 (2018) 
83. Xu M, Bradley EW, Weivoda MM, Hwang SM, Pirtskhalava T, Decklever T, Curran GL, Ogrodnik M, Jurk D, Johnson KO, Lowe V, Tchkonia T, Westendorf JJ, Kirkland JL: Transplanted senescent cells induce an osteoarthritis-like condition in mice. J. Gerontol. A Biol. Sci. Med. Sci. 72, 780-785 (2017)

84. Xu M, Palmer AK, Ding H, Weivoda MM, Pirtskhalava T, White TA, Sepe A, Johnson KO, Stout MB, Giorgadze N, Jensen MD, LeBrasseur NK, Tchkonia T, Kirkland JL: Targeting senescent cells enhances adipogenesis and metabolic function in old age. Elife 4, e12997 (2015)

85. Xu M, Pirtskhalava T, Farr JN, Weigand BM, Palmer AK, Weivoda MM, Inman CL, Ogrodnik MB, Hachfeld CM, Fraser DG, Onken JL, Johnson KO, Verzosa GC, Langhi LGP, Weigl M, Giorgadze N, LeBrasseur NK, Miller JD, Jurk D, Singh RJ, Allison DB, Ejima K, Hubbard GB, Ikeno Y, Cubro H, Garovic VD, Hou X, Weroha SJ, Robbins PD, Niedernhofer LJ, Khosla S, Tchkonia T, Kirkland JL: Senolytics improve physical function and increase lifespan in old age. Nat. Med. 24, 1246-1256 (2018)

86. Yousefzadeh MJ, Zhu Y, McGowan SJ, Angelini L, Fuhrmann-Stroissnigg H, Xu M, Ling YY, Melos KI, Pirtskhalava T, Inman CL, McGuckian C, Wade EA, Kato JI, Grassi D, Wentworth M, Burd CE, Arriaga EA, Ladiges WL, Tchkonia T, Kirkland JL, Robbins PD, Niedernhofer LJ: Fisetin is a senotherapeutic that extends health and lifespan. EBioMedicine 36, 18-28 (2018)

87. Zhang X, Zhang S, Liu X, Wang Y, Chang J, Zhang X, Mackintosh SG, Tackett AJ, He Y, Lv D, Laberge RM, Campisi J, Wang J, Zheng G, Zhou D: Oxidation resistance 1 is a novel senolytic target. Aging Cell, e12780 (2018) [Epub ahead of print]

88. Zhu Y, Tchkonia T, Fuhrmann-Stroissnigg H, Dai HM, Ling YY, Stout MB, Pirtskhalava T, Giorgadze N, Johnson KO, Giles CB, Wren JD, Niedernhofer LJ, Robbins PD, Kirkland JL: Identification of a Novel Senolytic agent, Navitoclax, targeting the Bcl-2 family of anti-apoptotic factors. Aging Cell 15, 428-435 (2016) 